\title{
The Impact of Geopolitical Risk on Systemic Risk Spillover in Commodity Market: An EMD-Based Network Topology Approach
}

\author{
Zhijing Ding $\mathbb{C}^{1}$ and Xu Zhang $\mathbb{C}^{2}$ \\ ${ }^{1}$ Changwang School of Honors, Nanjing University of Information Science \& Technology, Nanjing 210044, China \\ ${ }^{2}$ School of Management Science and Engineering, Nanjing University of Information Science \& Technology, \\ Nanjing 210044, China \\ Correspondence should be addressed to Zhijing Ding; dingzhijing1331@qq.com
}

Received 7 April 2021; Revised 29 May 2021; Accepted 8 June 2021; Published 1 July 2021

Academic Editor: Baogui Xin

Copyright (c) 2021 Zhijing Ding and Xu Zhang. This is an open access article distributed under the Creative Commons Attribution License, which permits unrestricted use, distribution, and reproduction in any medium, provided the original work is properly cited.

\begin{abstract}
Since the financialization of commodities, portfolio investments have become an important tool for investors to diversify risks. However, due to the nonlinear fluctuations brought about by extreme events, investors face more difficulties in the choice of risk portfolio. We adopt empirical mode decomposition and STVAR model, along with the basis data of optimized original sample interval. In addition, we retain the mature research of multiscale systemic risk under frequency and divide the dimension of systemic risk into two states. When frequency is combined with states, the risk spillover center undergoes subversive changes, particularly in the longest term, and metals become the risk spillover center, substituting the energy commodity, on the condition that the compositions of extreme value add persuasive power to the perspective of long term. We proposed that the joint fluctuation of agricultural commodities and energy commodities makes the former become another important risk spillover point. For investors, holding period and portfolio both need to be considered.
\end{abstract}

\section{Introduction}

When it comes to the commodity market, early studies generally focus on fluctuations of the commodity prices from the perspective of international trade, that is, the mechanism by which imports and exports disturb commodity price and change the commodity market structure, which is a microscopic analysis of the supply and demand relationship of commodities $[1,2]$. However, with the emergence of potential benefits in the commodity market, financial institutions and retail investors have substantially increased their exposures to commodities and have a net long-term position which has promoted the development of commodity financialization and gradually freed them from the shackles of the real economy, thus being decoupled from the simple dynamics of supply and demand [3-5]. Chen and Xiong said that market participants may dramatically raise asset prices and deviate from the fundamentals of supply and demand, making them highly volatile. This is such a closely related commodity market that it becomes a valuable investment tool and needs financialization [6]. Particularly, in 2004 when the "financialization" reached peak, commodity prices have undoubtedly become much more complicated [7]. To make matters worse, since the stock market crash in 2002, the risk diversification ability of commodity futures in cross-market transactions was discovered [8], which can be corroborated by the fact that the level of financial activity measured by the open interest in commodity futures has increased from 103 billion to 509 billion in few years [9]. The interest in analyzing systemic risk contagion from a macroperspective has become increasingly strong, both crossmarket or just inside the commodity market, and many scholars have been involved in this. From the perspective of risk theory, herding behavior is an important explanation in the field of behavioral finance when the joint fluctuations within the commodity market are mentioned, just taking energy and agricultural markets as example [10]. If intercommodity volatility is higher than the dynamics of the 
single commodity itself, the valuable incremental information containing in the former can be used to determine future price volatility. Other scholars have followed this thread and used the joint volatility of commodities as an opportunity to expand their heterogeneous performance in different economies. Commodity market is an important financial submarket. The volatility of commodities and the resulting dynamics of cross-commodity linkages are crucial to many aspects of finance, especially in investment portfolio and risk management $[12,13]$. Therefore, in such a situation where commodities have become the second largest evasive measure after equity assets, taking the requirements of investors for making reasonable decisions into account, it is of great significance to explore the risks of the commodity market.

Data with high volatility has become the main research object toward the current commodity market, and the higher the volatility, the higher the requirements for the portfolio risk control strategies $[14,15]$. We regard the commodity market as a large system, and different commodities are subsystems. By examining the impact of a certain commodity on the entire system when it is in trouble, in other words, extreme price shocks, we can concretize the systemic risk caused by joint fluctuations with $\mathrm{CoVaR}$, and $\mathrm{Co}$ represents joint functions [10]. Xu et al. have upgraded the intraday data commonly used in the empirical field [16] to a volatility calculated based on 5-minute prices [11]. The extensive use of high-frequency data has allowed systemic risk in the frequency domain to gain much attention, and the trend toward diversified risk has been applied in different investment periods, just like long term and short term. Taking oil market as an example, Gong and Lin pointed out that the commodity market has nonlinear characteristics [17], which puts forward further analysis of the performance of risk contagion in the commodity market under different states. The supply of oil is related to all aspects of the country's military and politics, and the geopolitical turmoil in the Middle East and Africa has increased geopolitical risk, even expanding to the economic field [18]. Bouoiyour et al. [19] and Su et al. [20] tested the possibility of combining geopolitical risk with commodity markets from a frequency perspective. The practice of replacing the entire economic system with macro-environmental indicators is very common in investigating the relationship between the external environment and various financial submarkets. Alqahtani et al. indicate that geopolitical risk is effective in linking stock prices to commodity markets [21]. Therefore, the multiscale analysis of the risk spillover in the commodity market under multiple conditions is closely related to the appetites for comprehensive risk diversification.

The existing literature on systemic risk spillover is insufficient. Many research works just concentrate on the external characteristics of the commodity index and lack the identification of the inherent characteristics of commodity volatility. In the meantime, many frontier studies based on the frequency domain only focus on single frequency domain or divide the state interval by external features, paying less attention to the state itself. The impact of variables such as endogenous variables on risk spillover is ignored. The main contributions of this article are as follows. Firstly, prescreening of samples is an innovative point of employing statistical ideas. We use the one-way variance decomposition to apply the precursor data widely used in earthquake prediction to identify irregular fluctuations in the commodity market, and examine the relevance of internal "system," which makes the research more pertinent and reasonable. Secondly, in research theory, we use the empirical mode decomposition method to explain the formation of systemic risk; that is, as a medium, the extreme value is composed of "peak superposition" and "continuous increase in amplitude," which work together to rationalize risk spillover. Thirdly, in application of the research mode, based on precursor data, we have enriched the current systemic risk research in the frequency domain, integrated the STVAR model into the empirical mode decomposition, and used the network diagram to show changes in risk centers and contagion paths under the influence of multiple frequencies and multiple states. We examine the joint volatility between different commodity markets and provide effective decision-making guidance for investors in diversifying risks in time and portfolio.

The rest of the paper is organized as follows. The next section describes the recent emerging literature on commodity market, including theoretical and applied perspectives. The subsequent section describes the methodology and data, and we present the results of our empirical analysis thereafter. The final section draws the main conclusions.

\section{Literature Review}

We arrange the papers in two ways. First of all, we report the literature on the study of systemic risk based on extreme value theory, mainly focusing on integrating extreme value factors into the computational systemic risk model, and we make necessary extensions to identify the characteristics of extreme value generation. Then, we compile the current literature on the nonlinearity of the commodity market based on macro variables, mainly focusing on the overall effect. Finally, we briefly explain the method used in this article.

Poon et al. demonstrate that extreme events play an important role in investment portfolios, and sometimes the only effective way to measure systemic risk is extreme value theory [22]. Li and Perez-Saiz use multivariate extremum methods to divide the whole financial market infrastructure into two or more FMIs to construct credit risk exposure indicators, and then estimate the systemic risk of the financial system [23]. Taking the banking system as an example, van Oordt and Zhou splits the systemic risk in dimensions to obtain the risk of a bank ("bank tail risk") and the link of the bank to the system in financial distress ("systemic linkage"), which distinguishes the micro and macro perspectives of research [24]. Di Clemente uses extreme value theory to expand the application range of systemic risk contribution measurement, allowing CoVaR to be realized in the macro system [25]. Motivated by the fact that the emergence of the 2007 financial crisis showed that the risk measures formulated so far did not achieve the 
expected performance, Gavronski and Ziegelmann innovatively constructed a new indicator, which uses the credit default swaps (CDS) of financial institutions as the data source, adding time dynamics, and finally formed the Financial System Dependence Index (FSDI) [26]. Extreme events are an important part of systemic risk, and tail characteristics are unique manifestations of financial markets. However, there are very few studies on extreme events themselves. In this article, we do not put extreme values into the model, but we analyze the components of extreme values from a theoretical perspective, looking forward to verifying the statement that "risks are often generated in a prosperous economic environment and then accumulate until it is activated" [27], which will also provide theoretical guidance for the use of monthly data. In parallel with the mainstream research, we continue to use CoVaR to examine the contagious effects of systemic risks in the commodity market. Systemic risks from the frequency perspective have become hot topics, which put forward new requirements for the selection of sample data. Bouri uses daily data to calculate the realized volatility and a time-varying parameter vector autoregressive model to analyze the risk spillover effect of the whole commodity market, representing high frequency [11]. Bakas and Triantafyllou weighted the daily excess return rate of each commodity to obtain the monthly achievable variance and finally discovered that the macro variable represented by economic uncertainty has a more lasting impact on the commodity market [28]. The Screening from the perspective of whether there exist systemic changes, being defined as the precursor data which better responds to the research on the formation mechanism of extreme values, we choose the monthly data. Similarly, based on the analysis in the frequency domain, this paper uses empirical mode decomposition instead of wavelet decomposition to investigate the internal trends of the commodity market.

Due to its high complexity, cross-border effects, random relationships, and nonlinear causal models with critical points, the negative impact of systemic risk has attracted more attention from scholars [29]. Asymmetric changes mean that there are different channels of infection, but considering the advantages of macroeconomic variables that can adjust commodity price fluctuations and enhance its stability [30-32], research from a macro perspective has been broadened [33, 34]. From simple regression and DCCGARCH model to even copula function, scholars measured the contagion effect of systemic risk in commodity market covered by macro factors [35-37]. Yang examined the timefrequency correlation between the economic uncertainty and the commodity market [38], while Chen et al. focused on the risk contagion of sovereign credit default swaps towards the entire system [39]. However, they focus on external characteristics but ignore the abnormal changes of macrofactors, which can be reached into consensus. Ignoring the possible institutional transformation effects in the risk contagion, along with using the traditional linear framework for analysis, may lead to obvious deviations in conclusions which has explained by Teräsvirta [40]. Therefore, it is of great significance to study the nonlinear risk contagion. The introduction of indicators of economic policy uncertainty will weaken the impact of systemic risk, especially when there are strong differences in economic policies, coinciding with the view that the essence of systemic risk is its internal periodicity [27]. Some studies examine the impact of transitions in states on risk spillover from the perspective of quantile regression [10], using externally delineated state frequencies as the standard for state distinction, which is universal. Under the guidance of Markov characteristics, evaluation of system risk in different states in the network is considered as well [41], but none of them utilize the inherent properties of unique state variables. In era of endless geopolitical conflicts, the macro variable of geopolitical risk has penetrated into the financial market through its linkage with commodity trading, and its application is of immediate significance. We quote the STVAR model, in which GPR functions as an endogenous variable, and exploit its inherent characteristics to divide the expansion and recession state to compare changes of risk spillover.

With the continuous development of modern econometric methods, sociological network analysis has been widely used. Unlike Liu and Jiang [42], we only use weighted out-degree as the indicator of the network, for symmetrical out-degree and in-degree in Gephi. However, the same as Billio et al. [43], we will analyze the risk center and the path of infection, since the aggregation part of the network diagram will reveal the joint fluctuations of different categories of commodities.

\section{Methodology and Data}

3.1. Precursor Data. Precursor refers to the factor that drives changes in an event, that is, the symptoms before it occurs. At present, precursor research is widely used in natural science such as earthquake prediction, geological mining, and engineering geology [44-46], but it is rarely applied in the financial field. The precursor data sample containing the important generation information of extreme data [47] may improve the accuracy of risk spillover analysis. Too much sample data will bring about information redundancy and misjudgment, while too little sample data will lose important information and reduce recognition efficiency. Appropriate precursor data and sample intervals are critical to the validity of the results $[48,49]$. Therefore, this paper uses precursor data as the basis to study the extreme value evolution information which is implicit in the sample, so as to provide a more effective data source for measuring systemic risk. Due to the uncertainty of extreme fluctuations[50], it is still difficult to directly observe and determine the generation interval throughout the whole time scale, and the results may be different by different sample intervals. Based on this, this paper draws on the one-way analysis of variance, constructs the F statistic to identify the difference between the hidden information inside the data, and determines the length of the precursor data sample.

Assuming that the total length of the time series data sample is $N$ and that of single precursor data sample is $n$, all the sample data is divided into subsamples by $N / n$. Then, we select two adjacent subsamples and use the statistical 
properties of one-way analysis of variance [51] to determine whether to reject the null hypothesis, that is, whether the "precursor" of the extreme event has changed, meaning that whether there is any systemic difference between adjacent samples. If this difference is not statistically significant, this means that the two samples are very similar; in other words, there is no important information that implies the generation of extreme values and vice versa. Then, we change the sample length $n$ and continue to repeat the above operation until a significant $F$ statistic is determined. With reference to the classic principle of analysis of variance, this paper uses the sum of squares to express the degree of volatility in which the difference between mutual groups can be measured. The total sum of squares (SST) represents the fluctuations caused by systemic factors and shock factors. The error sum of squares (SSE) represents the internal fluctuations of a single sample. It also includes the explicit influence of external shocks and the implicit influence of extreme value generation information. The sum of squares between groups (SSA) represents volatility between samples. In order to avoid the influence of sample size, the method of dividing by degrees of freedom is customarily adopted; that is, after dividing by degrees of freedom $n-k$ and $k-1$ in turn, SSE and SSA become MSA and MSE, respectively. $K$ represents the number of factor levels which corresponds with the number of sample groups, being equal to 2 in this paper. Among them, $\left(x_{i j}-\bar{x}_{j}\right)^{2}$ represents the difference between the sample observation value and the sample mean, and $n_{j}\left(\bar{x}_{j}-\bar{x}\right)^{2}$ represents the difference between the sample mean and the overall mean.

$$
\begin{aligned}
\mathrm{SST} & =\mathrm{SSE}+\mathrm{SSA}, \\
\mathrm{SSE} & =\sum_{j=1}^{k} \sum_{i=1}^{n_{j}}\left(x_{i j}-\bar{x}_{j}\right)^{2}, \\
\mathrm{SSA} & =\sum_{j=1}^{k} \sum_{i=1}^{n_{j}}\left(\bar{x}_{j}-\bar{x}\right)^{2}=\sum_{j=1}^{k} n_{j}\left(\bar{x}_{j}-\bar{x}\right)^{2}, \\
F & =\frac{\operatorname{MSA}}{\operatorname{MSE}}=\frac{(\mathrm{SSA} /(k-1))}{(\mathrm{SSE} /(n-k))} \sim F(k-1, n-k) .
\end{aligned}
$$

3.2. Empirical Mode Decomposition. In view of the in-depth application of precursor data in nonfinancial fields, frequency domain analysis has become a classic research paradigm [52, 53], such as Fourier transform, wavelet transform, and empirical mode decomposition. Fourier transform is one of the important methods of signal processing. After Fourier transform, various frequency components contained in the signal sequence can be obtained, but the time information of the signal is ruled out, making it difficult to confirm the timing of important properties such as transient characteristics. The wavelet transform links the frequency domain information of the signal with the time domain information and overcomes the shortcomings of the Fourier transform. However, the wavelet transform provides a time-frequency domain window with a variable scale, but without infinite high resolution in both the time domain and the frequency domain. In addition, different wavelet bases will affect the analysis results, while empirical mode decomposition (EMD) with good adaptability can decompose signals based on the time-scale characteristics of the data itself, without setting any prior wavelet basis functions [54]. Taking the extreme values and irregular fluctuations of financial time series data into account, this paper does not use Fourier transform and wavelet transform but uses EMD for data preprocessing.

The main idea of empirical mode decomposition is to transform an irregular frequency wave into multiple waves of single frequency (IMF) plus residual wave (residual). IMF meets two conditions: the functions have the same numbers of extrema and zero-crossings or differ at the most by one, and the functions are symmetric with respect to local zero mean. The two conditions ensure that an IMF is nearly periodic function and the mean is set to zero. IMF is a harmonic-like function, but with variable amplitude and frequency at different times. Inside the EMD model, the IMFs are extracted through a shifting process following six steps [55]: Firstly, we identify all the maxima and minima of time series $x(t)$. In the second step, we generate its upper and lower envelopes, $e_{\max }(t)$ and $e_{\min }(t)$, with cubic spline interpolation. In the third step, we calculate the point-bypoint mean $(m(t))$ from upper and lower envelopes, which is as follows:

$$
m(t)=\frac{e_{\max }(t)+e_{\min }(t)}{2} .
$$

In the fourth step, we extract the mean from the time series and define the difference of $x(t)$ and $m(t)$ as $d(t)$ :

$$
d(t)=x(t)-m(t)
$$

In the fifth step, we check the properties of $d(t)$ : if it is an IMF, denote $d(t)$ as the ith IMF and replace $x(t)$ with residual $r(t)=x(t)-d(t)$. The $i$ th IMF is often denoted as $c_{i}(t)$ and the $i$ is called its index; if it is not, replace $x(t)$ with $d(t)$. Finally, we repeat steps one to five until the residual satisfies some stopping criterion.

One stopping criterion proposed by Huang et al. [56] for extracting an IMF is still applied, iterating predefined times after the residue satisfies the restriction that the numbers of zero-crossings and extrema do not differ by more than one and the whole sifting process can be stopped by any of the following predetermined criteria: either when the component $c_{i}(t)$ or the residue $r(t)$ becomes so small such that it is less than the predetermined value of a substantial consequence, or when the residue $r(t)$ becomes a monotonic function from which no more IMFs can be extracted. The total number of IMFs is limited to $\log _{2} N$, where $N$ is the length of data series. The original time series can be expressed as the sum of some IMFs and a residue:

$$
x(t)=\sum_{j=1}^{N} c_{j}(t)+r(t),
$$

where $N$ is the number of IMFs and $r(t)$ means the final residue. 
3.3. Smooth-Transition Vector Autoregression (STVAR). In order to characterize the nonlinear relationship of economic variables in different state intervals, Sims [57] made a pioneering exploration of vector autoregressive models and then developed a series of nonlinear VAR models. Among them, Markov-Switching Vector Autoregression (MSVAR), Threshold Vector Autoregression (TVAR), and SmoothTransition Vector Autoregression (STVAR) are widely used. In the STVAR model, the state variables that drive interval transitions are preset observable variables and support continuous transition mechanisms, which have strong explanatory power for the economy. Within the framework of the STVAR model, according to the different settings of the conversion function, it can be subdivided into Logistic Smooth-Transition Vector Autoregression (LSTVAR) model and Exponential Smooth-Transition Vector Autoregression (ESTVAR) model. The former can describe the high state variable interval and the low state variable interval. The asymmetry mechanism of the state variable interval and the ESTVAR model is mainly used to reflect the transition of the symmetric interval [40].

In order to examine the asymmetric contagion mechanism of GPR on the commodity market which may correspond to the wave properties of different frequency series under EMD, we refer to the research of Caggiano et al. [58], thus establishing the following model:

$$
\begin{aligned}
Y_{t} & =\left[1-F\left(z_{t-1}\right)\right]\left[\prod_{b}^{p} Y_{t-1}+F\left(z_{t-1}\right) \prod_{g}^{p} Y_{t-1}+\varepsilon_{t}\right], \\
\varepsilon_{t} & \sim N(0, \Omega), \\
F\left(z_{t}\right) & =\left\{1+\exp \left[-\gamma\left(z_{t}-c\right)\right]\right\}^{-1}, \quad \gamma>0, E\left(z_{t}\right)=0, \\
& \operatorname{Var}\left(z_{t}\right)=1,
\end{aligned}
$$

where $Y_{t}$ represents a set of endogenous variables that are partly selected from the commodity market. $F\left(z_{t}\right)$ is a logistic transition function which is used to describe the probability of the sample being divided into different "economic states" (recession and expansion at GPR). The nonnegative parameter $\gamma$ determines the rapidity of the switch from a regime to another (the higher the $\gamma$, the faster the switch), and $z_{t}$ is a state variable used to capture the periods of GPR. $c$ is the threshold parameter identifying the two regimes. $\prod_{b}^{p} Y_{t}$ and $\prod_{g}^{p} Y_{t}$ indicate the coefficient matrix of GPR in two regimes, and $\varepsilon_{t}$ is the vector of reduced-form residuals obeying a normal distribution.

In function (5), $Y_{t}$ is the endogenous variables of STVAR model including state variable and CoVaR of each commodity at specific period which represents cocoa $(\mathrm{Cc})$, wheat $(\mathrm{Wh})$, corn $(\mathrm{Cr})$, orange juice $(\mathrm{Oj})$, nickel $(\mathrm{Ni})$, sliver $(\mathrm{Si})$, lean hogs $(\mathrm{Lh})$, crude oil $(\mathrm{CO})$, unleaded gas $(\mathrm{Ug})$, natural gas $(\mathrm{Ng})$, live cattle $(\mathrm{Lc})$, aluminum $(\mathrm{Al})$, and heating oil (Ho). $z_{t}$ is the state variable processed by filtering, and the parameters is processed with maximum likelihood. The estimation model is $Y_{t}=\left[z_{t}, \mathrm{Cc}_{t}\right.$, $\left.\mathrm{Wh}_{t}, \mathrm{Cr}_{t}, \mathrm{Oj}_{t}, \mathrm{Ni}_{t}, \mathrm{Si}_{t}, \mathrm{Lh}_{t}, \mathrm{CO}_{t}, \mathrm{Ug}_{t}, \mathrm{Ng}_{t}, \mathrm{Lc}_{t}, \mathrm{Al}_{t}, \mathrm{HO}_{t}\right]$.
3.4. Risk Spillover Network. Network analysis also plays an important role in measuring systemic risks, because this analysis can better model and predict the behavior of complex financial systems, in which the center and contagion channel can be vividly observed. It is worth mentioning that, for the stability of the system as a whole, what is needed is a risk-based systemic approach; that is, the systemic risk is used as the original data. Existing research works show that systemic factors and random shock factors jointly drive sequence fluctuations. What is more, the important information of extreme value generation is implicit in shock factors, and systemic factors run through all sequence data [59-61]. EMD shows the formation process of extreme value fluctuations in a single commodity rate of return sequence, and then the impact of single commodity system fluctuations into the overall system is manifested through the stability of the network as mentioned above, even forming risk spillover. We adopted the typical network topology method proposed by Diebold and Yilmaz [62], which is the prototype of many other network analyses. We construct the following risk spillover matrix based on the prediction error variance decomposition, which shows the specific definition, as shown in Table 1.

In the spillover matrix in the table, the variables in the first row represent the source of risk spillovers, and the vectors in the first column denote the entity receiving the risk. We can calculate the degree of pairwise risk spillover based on the following decomposition:

$$
S_{i \leftarrow j}^{H}=\frac{\sum_{h=0}^{H-1} a_{i j, h}^{2}}{\sum_{h=0}^{H-1} \operatorname{trace}\left(A_{h} A_{h}^{\prime}\right)},
$$

where $\sum_{h=0}^{H-1} a_{i j, h}^{2}$ is the error variance of the risk in commodity $i$ in forecast period $H$ caused by the impact of risk in commodity $j$, and $\sum_{h=0}^{H-1} \operatorname{trace}\left(A_{h} A_{h}^{\prime}\right)$ represents total forecast error variance in period $H$. Therefore, the above exhibits the proportion of single commodity. In general, $S_{i \leftarrow j}^{H} \neq S_{j \leftarrow i}^{H}$; we can define the effect of the net risk spillovers from commodity $j$ to commodity $i$ using the following formula:

$$
N S_{i \leftarrow j}^{H}=S_{i \leftarrow j}^{H}-S_{j \leftarrow i}^{H} .
$$

Moreover, the items in the "OUT" row denote the total items on the nondiagonal lines in each column, allowing us to measure the spillovers from commodity $j$ to other commodities. The "IN" column and the total net effect are similar:

$$
\begin{aligned}
T S_{\mathrm{OUT}, \leftarrow j}^{H} & =\sum_{i} S_{i \leftarrow j}^{H}, \quad \text { for } i \neq j, \\
T S_{\mathrm{IN}, i \leftarrow .}^{H} & =\sum_{i} S_{i \leftarrow j}^{H}, \quad \text { for } i \neq j, \\
N T S_{i}^{H} & =T S_{\mathrm{OUT}, \leftarrow j}^{H}-T S_{\mathrm{IN}, i \leftarrow}^{H}=\sum_{i} N S_{j \leftarrow i}^{H} .
\end{aligned}
$$

In addition, we can measure the overall system-wide total spillover effectively by summing and taking the average of the items in the "OUT" row or the "IN" column, as follows: 
TABLE 1: Definition of risk spillover networks.

\begin{tabular}{lccccc}
\hline & $\Delta \mathrm{IV}_{1}$ & $\Delta \mathrm{IV}_{2}$ & $\ldots$ & $\Delta \mathrm{IV}_{n}$ & $\mathrm{IN}$ \\
\hline$\Delta \mathrm{IV}_{1}$ & $S_{1 \leftarrow 1}^{H}$ & $S_{1 \leftarrow 2}^{H}$ & $\ldots$ & $S_{1 \leftarrow n}^{H}$ & $\sum_{i} S_{1 \leftarrow j}^{H}, j \neq 1$ \\
$\Delta \mathrm{IV}_{2}$ & $S_{2 \leftarrow 1}^{H}$ & $S_{2 \leftarrow 2}^{H}$ & $\ldots$ & $S_{2 \leftarrow n}^{H}$ & $\sum_{i} S_{2 \leftarrow j}^{H}, j \neq 1$ \\
$\ldots$ & $\ldots$ & $\ldots$ & $\ldots$ & $\ldots$ & $\ldots$ \\
$\Delta \mathrm{IV}_{n}$ & $S_{n \leftarrow 1}^{H}$ & $S_{n \leftarrow 2}^{H}$ & $\ldots$ & $S_{n \leftarrow n}^{H}$ & $\sum_{i} S_{n \leftarrow j}^{H}, j \neq 1$ \\
OUT & $\sum_{i} S_{i \leftarrow 1}^{H}, i \neq 1$ & $\sum_{i} S_{i \leftarrow 2}^{H}, i \neq 2$ & $\ldots$ & $\sum_{i} S_{i \leftarrow n}^{H}, i \neq n$ & $\frac{1}{N} \sum_{i} S_{i \leftarrow j}^{H}, i \neq j$ \\
\hline
\end{tabular}

$$
\begin{aligned}
S T S_{i}^{H} & =\frac{1}{N} \sum_{i} T S_{\mathrm{IN}, i \leftarrow .}^{H}=\frac{1}{N} \sum_{i} T S_{\mathrm{OUT}, \leftarrow j}^{H} \\
& =\frac{1}{N} \sum_{i} \sum_{j} S_{j \leftarrow i}^{H}, \quad \text { for } i \neq j .
\end{aligned}
$$

3.5. Data. When selecting samples, we do not consider energy trading indexes, such as Energy TR, because we focus on the three main categories of commodity markets: agriculture, metals, and energy. Considering the requirement of calculating systemic risk, we have selected market indexes (CRB) in the corresponding range. Considering the uniformity of the EMD, we only selected 13 commodity indexes to quantify the risk spillover between commodities from all the 16 commodities (the IMFs decomposed by sugar, soybeans, and gold are 3, 5, and 5, which are against the four IMFs of commodities). We choose global geopolitical risk to examine the spread of risks, even till commodity markets [63]. Since geopolitical risk (GPR) is monthly, in order to ensure data consistency, we choose monthly commodity index. In the meantime, providing the availability of data on the investing website, the initial sample was finally confirmed, from July 2005 to March 2021, with a total of 189 observation months. The logarithmic rate of return is the basis for calculating systemic risk, and we select the closing price of the 13 commodity indexes for calculation. As for the geopolitical risk index, we additionally perform HP filtering (Hodrick-Prescott filter) processing on it [59], because as a state variable in the STVAR model, it needs to have more obvious periodic attribute.

Figure 1 shows the fluctuations of GPR throughout 189 months, which shows an upward trend as a whole, and the purple shading marks the local maximum extreme points. In the past ten years, the global bulk commodity market has shown the following three trends: Major agricultural products fluctuated sharply at a relatively high level, especially undergoing a rapid rise from 2010 to 2011. Energy is showing a trend of upward volatility, and GPR seems to play an indispensable role in it, even being more pushing than other macro indicators [64]. However, after the gradual fading of the 9/11 incident and the breakthrough of the bottleneck in 2006, the metal just ushered in a rise. In order to further understand the mode of functioning extreme values, as to whether particular regularity exists, we sort out

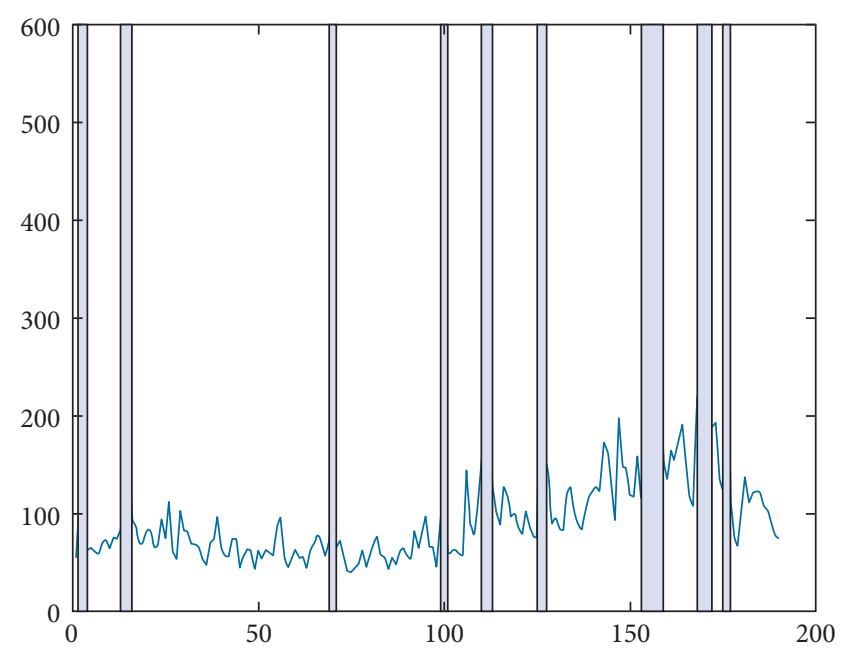

FIGURE 1: GPR index throughout 189 months.

the most effective precursor data according to the aforementioned research design.

Taking the actual observational law on extremum into consideration, it is uncommon to have multiple extrema within a month. Two or more consecutive fluctuations caused by one shock are usually regarded as one extremum. Therefore, the shortest precursor data sample period should be greater than one month, and the maximum period should not exceed one year, which match the habit of conducting economic accounting on an annual cycle. Based on this, we take half a year ( 6 months) and the first quarter ( 3 months) for one-element analysis of variance. Taking 3 months as a group, we found that, at a significance level of $10 \%$, more possible subsamples will be generated, which meets the need for more samples for subsequent state decomposition. The entire data can be divided into 63 subsamples which are denoted as $S_{i}, i=1,2, \ldots, 63$, respectively. The samples that meet the definition of precursor data are the bold subsamples in Table 2, and there are 24 groups, for 72 observable months.

According to the F statistic, at a significance level of $10 \%$, the above-mentioned 14 pairs of blackened samples all show strong rejection of the null hypothesis information; that is to say, extreme value generation information is most likely to be generated in this sample interval, since the statistic reaches its maximum locally. The excluded samples only reflect the "normal" data generation process and do not contain the important information of extremum generation; thus, those will not affect the accuracy of extremum analysis, which means that the elimination of some "redundant" samples greatly reduces the number of original samples to be studied. The precursor data sample improves the efficiency of extremum risk detection. Then, we associate the sample with time. The time period corresponding to S2-S6 is 200510 to $2006-12, S 10-S 11$ is $2007-10$ to $2008-03$, and S21-S22 is 2010-07 to 2010-12. The time period corresponding to S24$S 25$ is 2011-04 to 2011-09, S27-S28 is 2012-01 to 2012-06, S30-S31 is $2012-10$ to 2013-03, and S36-S38 is 2014-04 to 2014-12. Finally, the period corresponding to $S 39-S 40$ is 2015-01 to 2015-06, $S 47-S 48$ is 2017-01 to 2017-06, and 
TABle 2: Precursor data.

\begin{tabular}{lccccc}
\hline Sample & $F$ value & $P$ value & Sample & $F$ value & $P$ value \\
\hline S1-S2 & 1.539 & 0.283 & $S 17-S 18$ & 0.698 & 0.450 \\
S2-S3 & 4.793 & $\mathbf{0 . 0 9 4}$ & S18-S19 & 0.003 & 0.961 \\
S3-S4 & 4.744 & $\mathbf{0 . 0 9 5}$ & S19-S20 & 0.324 & 0.600 \\
S4-S5 & 6.175 & $\mathbf{0 . 0 6 8}$ & S20-S21 & 0.251 & 0.643 \\
S5-S6 & 6.462 & $\mathbf{0 . 0 6 4}$ & S21-S22 & 8.173 & $\mathbf{0 . 0 4 6}$ \\
S6-S7 & 0.054 & 0.827 & S22-S23 & 0.245 & 0.646 \\
S7-S8 & 0.004 & 0.952 & S23-S24 & 0.805 & 0.420 \\
S8-S9 & 0.006 & 0.944 & S24-S25 & 22.907 & $\mathbf{0 . 0 0 9}$ \\
S9-S10 & 0.387 & 0.567 & S25-S26 & 3.036 & 0.156 \\
S10-S11 & 7.905 & $\mathbf{0 . 0 4 8}$ & S26-S27 & 4.218 & 0.109 \\
S11-S12 & 2.631 & 0.180 & S27-S28 & 5.092 & $\mathbf{0 . 0 8 7}$ \\
S12-S13 & 3.660 & 0.128 & S28-S29 & 0.251 & 0.643 \\
S13-S14 & 2.345 & 0.200 & S29-S30 & 0.391 & 0.566 \\
S14-S15 & 0.149 & 0.719 & S30-S31 & 5.593 & $\mathbf{0 . 0 7 7}$ \\
S15-S16 & 0.053 & 0.829 & S31-S32 & 0.040 & 0.850 \\
S16-S17 & 0.275 & 0.628 & S32-S33 & 0.307 & 0.609 \\
S33-S34 & 1.312 & 0.316 & $S 49-S 50$ & 0.334 & 0.594 \\
S34-S35 & 0.821 & 0.416 & $S 50-S 51$ & 0.802 & 0.421 \\
S35-S36 & 0.011 & 0.920 & S51-S52 & 1.988 & 0.231 \\
S36-S37 & 18.894 & $\mathbf{0 . 0 1 2}$ & S52-S53 & 0.505 & 0.516 \\
S37-S38 & 10.658 & $\mathbf{0 . 0 3 1}$ & S53-S54 & 0.189 & 0.686 \\
S38-S39 & 0.188 & 0.687 & S54-S55 & 0.106 & 0.761 \\
S39-S40 & 5.058 & $\mathbf{0 . 0 8 8}$ & S55-S56 & 0.438 & 0.544 \\
S40-S41 & 0.006 & 0.942 & S56-S57 & 0.277 & 0.627 \\
S41-S42 & 2.186 & 0.213 & S57-S58 & 3.567 & 0.132 \\
S42-S43 & 1.019 & 0.370 & S58-S59 & 0.209 & 0.671 \\
S43-S44 & 0.406 & 0.558 & $S 59-S 60$ & 0.906 & 0.395 \\
S44-S45 & 0.411 & 0.556 & S60-S61 & 0.455 & 0.537 \\
S45-S46 & 0.094 & 0.774 & S61-S62 & 0.983 & 0.378 \\
S46-S47 & 4.320 & 0.106 & S62-S63 & 13.351 & $\mathbf{0 . 0 2 2}$ \\
S47-S48 & 8.087 & $\mathbf{0 . 0 4 7}$ & & & \\
\hline & & & & &
\end{tabular}

S62-S63 is 2020-10 to 2021-03. Based on the time correlation of the above samples, the generation period range of extremum can be determined, and investors can hedge extremum risks and even predict part of systemic risk. The supervisory authority can select the early warning time to provide a preliminary risk disposal window. The 14 pairs of precursor data samples are further analyzed below, and the extremum generation law is further identified through EMD method.

The volatility of return has significant nonlinear characteristics $[53,65,66]$. In order to verify the rationality of the application of precursor data and STVAR model, plus the necessity of measuring systemic risk, we then perform the following mutation test. In this paper, BDS test [67], Chow test [68], and Quandt-Andrews test $[69,70]$ are used to test the stability of model parameters, which are constructed under the rate of return. Among them, Chow test is a known mutation point test, while Quandt-Andrews test is unknown points. Due to the small amount of sample data, for the BDS test in Table 3, EViews only supports nesting dimensions of 2,3 , and 4 . The results show that the null hypothesis of independent and identical distribution is significantly rejected, indicating that there is a nonlinear relationship between the variables. The mutation point test indicates that the parameters of the model contain one or more mutation points, which means that the use of constant parameter estimation methods will lead to biased estimation results. In the Chow test, the known mutation points also appear in the precursor data reflecting the formation of extremum in Table 2, proving the rationality of applying the precursor data. The above sample selection and mutation test are based on the logarithmic rate of return.

\section{Empirical Results}

In this paper, we take the "disturbance" generated by extreme events as the starting point and define the sample as precursor data, which can be used as a driving factor to promote the generation of systemic differences, in turn contributing to the measurement of systemic risk. When the driving factors change, the future performance in the near future will be inevitably affected, which imposes higher demands on investors and regulators. Firstly, the EMD performs frequency decomposition according to the intrinsic attributes of the commodity index and obtains 5 frequencies which are denoted as IMF1, IMF2, IMF3, IMF4, and residual, respectively, representing high frequency (short term), low frequency (long term), and trend items. In addition, the IMF2 can be called medium-high frequency and the IMF3 can be called medium-low frequency. The signal in the figure represents the original time series. Then, using the GARCH-CoVaR model (Xu et al. argued that the method is effective) [71], the system risk in 13 commodities was obtained. This is the basic data for STVAR model and network analysis.

4.1. Empirical Mode Decomposition (EMD). From Figures 2-4, we can see that all the decomposed IMFs gradually move from high frequency to low frequency, and their amplitude gradually increases. In addition, the last trend item is a time sequence for long-term trend of logarithmic rate of return of different commodities, which are described as the inner trajectory of the original sequence [55]. Both cocoa and natural gas are in a fluctuating state. The former rises after falling, while the latter rises and maintains fluctuations. "Live cattle" rises monotonically. Since the space of article is limited, we randomly selected one of the three types of commodity markets as a representative to show the effect of empirical mode decomposition, and take these three commodities as instances to analyze the main process of extremum formation and provide theoretical support for systemic risks.

When analyzing shocks in a typical sequence, the effects of shocks are usually viewed from the peak value, such as instantaneous, short-term and long-term effects. Shocks promote the formation of extreme values, and continuous shocks will drive the generation of systemic risks. Therefore, we start with peak value and look at the reflection of commodities in different frequency domains. We can grasp the following from the pattern of stock prices: if the stock price keeps rising without a callback, market risks will continue to accumulate, and even plummet and skyrocketing will occur, prompting the generation of extreme values, thereby finally making systemic risks high. However, 
TABLE 3: Mutation point test.

\begin{tabular}{|c|c|c|c|c|c|}
\hline \multicolumn{2}{|c|}{ BDS test at IMF1 } & \multicolumn{2}{|c|}{ Quandt-Andrews test at IMF1 } & \multicolumn{2}{|c|}{ Chow test at IMF1 } \\
\hline Dimension & $Z$ statistic & Statistic & Value & Breaks & LLR $F$ statistic \\
\hline 2 & $4.495935^{* * *}$ & Max LR & $4.217101^{* * *}$ & 2011.08 & $1.689893^{* * *}$ \\
\hline 3 & $4.321284^{* * *}$ & Exp LR & $1.420065^{* * *}$ & 2013.03 & $3.549565^{* * *}$ \\
\hline 4 & $4.289628^{* * *}$ & Ave LR & $2.583096^{* * *}$ & 2015.01 & $2.019895^{* * *}$ \\
\hline \multicolumn{2}{|c|}{ BDS test at IMF4 } & \multicolumn{2}{|c|}{ Quandt-Andrews test at IMF4 } & \multicolumn{2}{|c|}{ Chow test at IMF4 } \\
\hline 2 & $11.06079^{* * *}$ & Max LR & $137.18^{* * *}$ & 2011.08 & $108.105^{* * *}$ \\
\hline 3 & $10.69458^{* * *}$ & Exp LR & $65.88216^{* * *}$ & 2013.03 & $22.81301^{* * *}$ \\
\hline 4 & $11.51872^{* * *}$ & Ave LR & $77.28582^{* * *}$ & 2015.01 & $6.461639^{* * *}$ \\
\hline
\end{tabular}

All data come from investing website, throughout 72 months. For the limited space, only two IMF components are displayed, and the rest are available on request. The BDS test is based on the residual series. ${ }^{*},{ }^{* *}$, and ${ }^{* * *}$ represent the significance test in which the model passed, respectively, under $10 \%, 5 \%$, and $1 \%$.

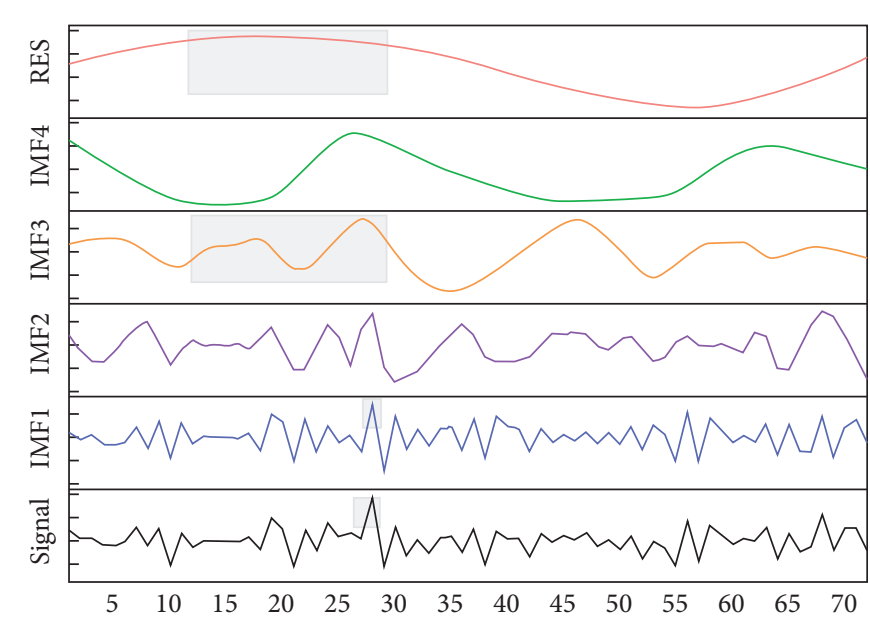

Figure 2: EMD under cocoa.

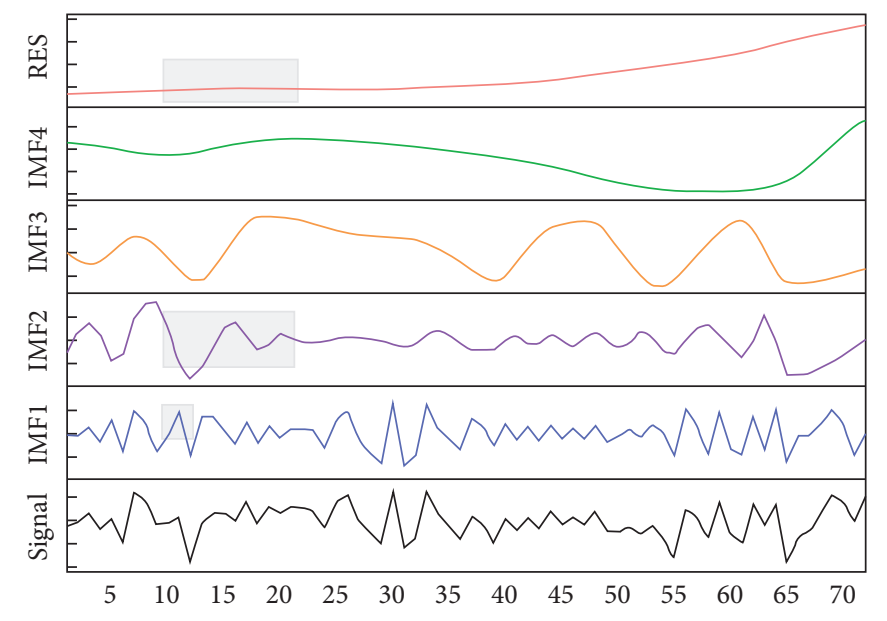

FIgURE 4: EMD under natural gas.

if the stock price is rising in a downward trend, the possibility of extreme value is relatively small, and the systemic risk is diversified. Based on this, we call the sequence that fluctuates periodically and becomes larger and larger at amplitude "continuous increase in amplitude," but there is no periodic feature and only the continuous increase in amplitude is called "peak superposition". What matters is whether the sign of "decay" was released.

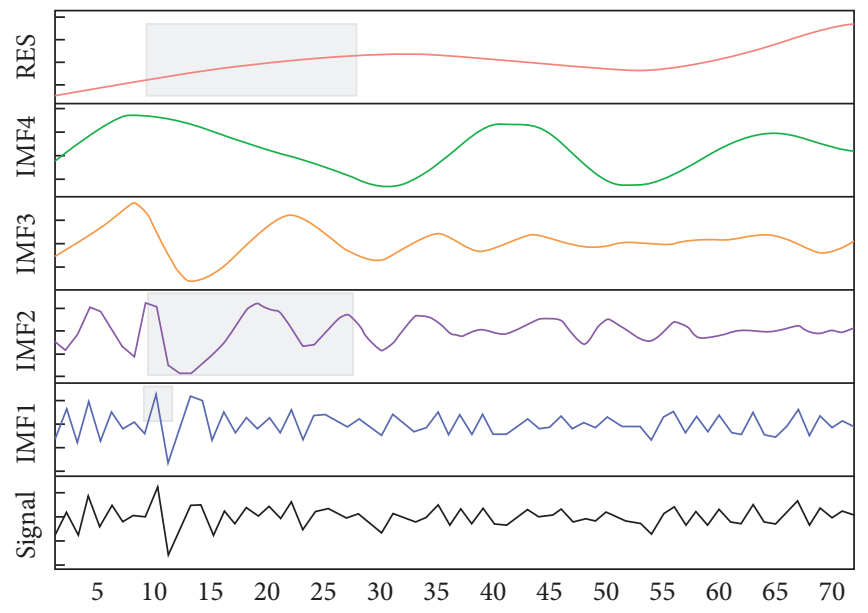

Figure 3: EMD under live cattle.

In IMF1 representing the high frequency of Figure 2, we can clearly see that there are several obvious transitions, and we choose the transition within the scale 25-30 for analysis. In IMF3 representing low frequency, the characteristics of "continuous increase in amplitude" can be observed, while in the RES sequence that reflects the market trend [55], "peak superposition" is observed, and there is even no fallback displacement in the 0-25 segment, so cocoa generated an extremum at the corresponding position of the signal sequence, and the specific features have been marked with grey shadows in the figure. Similar analysis exists in Figure 3. Due to the significant "continuous reduction in amplitude" in IMF2 at scale 5-10, which offsets the "peak superposition" in the corresponding RES sequence, live cattle did not generate extreme values in the corresponding scale. However, in the scale 55-65, the shock appears and the following characteristics exist; thus, the extremum is shown naturally, which proves that combining the image features to explore the generation law is reasonable. The same is true for Figure 4, and the entire sequence of natural gas is relatively stable, compared to the previous two.

The frequency and amplitude of IMFs change over time, so that the period is not a constant value. Drawing lessons from Xia and Li [72], we use the fast Fourier transform method to calculate the IMF period. Because the commodity 
market price is affected by many factors [73], there is a small amount of "noise" in the spectrum, but the frequency of identifying the rate of return based on the peak in the power is still valid, and finally Table 4 is obtained. As far as the energy sequence is concerned, there is no significant increase or decrease in the period of transition from high frequency to low frequency, which can be understood as being in the center for a long time, which needs verifying. Only heating oil shows a sharp rise at high frequency. For metals, given their main attributes as substitutes, they are susceptible to external good or bad news and the risk transmission between commodities, such as the mutual fluctuations between oil prices and gold [74]. In contrast, agricultural products, as daily necessities, are stable, but due to certain force majeure effects, there is a lag in the transition to the low-frequency part, such as African swine fever. This may provide possible support for subsequent risk spillover network analysis.

\subsection{Smooth-Transition Vector Autoregression (STVAR)} Model Based on EMD. In the empirical mode decomposition, we obtain 4 frequency series. By analyzing the changing characteristics of the sequence, we converted some rules of extremum formation. The extreme value is a manifestation of systemic risk. Analyzing the contribution of different commodities to the entire commodity market constitutes systemic risk. From the previous analysis, the original time series exhibited nonlinear properties. Based on the unique performance of individual commodities in large categories of commodities, and the significant periodic differences between different frequencies, we will use frequency as the entry point. We use the STVAR model, combined with network analysis, and then try to analyze what functions as the center in the commodity market under different conditions at the same frequency and what the specific risk infection channels are.

Many research works involving commodity markets focus on GPR. When it comes to the external shock making a difference to the commodity market, the geopolitical risk won much attention. We continue to use geopolitical risk, a macroeconomic variable, to be linked to the overall macro environment [11]. The focus of the STVAR model is the state variable, which refers to GPR in this paper. The conversion of the state variable divides the original data into upward and downward intervals, that is, expansion and recession. With the year 2000 being considered as the boundary, NogueraSantaella points out the asymmetry of GPR on the aspects of oil volatility [75], which coincides with the nonlinearity of the commodity market [12]. In the STVAR model, we regard the forecast periods as 60 . The following data takes the 60th period as an example (we observed the risk spillover centers of periods $4,8,16,32$, and 60 , respectively, and they are all consistent; the results are available on request). The basic data of STVAR is systemic risk. According to the SC criterion, the optimal lag order of basic VAR model is determined as 2. After estimating the GARCH-CoVaR model, 4 groups of systemic risk values are obtained.

As shown in Tables 5 and 6, we only select recession and expansion under IMF1 for display, and the results of other
TABLE 4: Fluctuation period under all IMFs.

\begin{tabular}{lcccc}
\hline & IMF1 & IMF2 & IMF3 & IMF4 \\
\hline $\mathrm{Cc}$ & 2.133333333 & 9.142439203 & 17.99856012 & 35.99712023 \\
$\mathrm{Wh}$ & 3.428532245 & 8 & 12.00048002 & 71.99424046 \\
$\mathrm{Cr}$ & 2.117657024 & 17.99856012 & 10.28594939 & 23.99808015 \\
$\mathrm{Oj}$ & 3.00003 & 7.1999424 & 10.28594939 & 71.99424046 \\
$\mathrm{Lc}$ & 3.27267967 & 5.999880002 & 14.40092166 & 71.99424046 \\
$\mathrm{Ni}$ & 2.32255667 & 10.28594939 & 17.99856012 & 71.99424046 \\
$\mathrm{Si}$ & 2.32255667 & 8 & 17.99856012 & 23.99808015 \\
$\mathrm{Lh}$ & 2.057147559 & 9.000090001 & 10.28594939 & 71.99424046 \\
$\mathrm{Al}$ & 3.00003 & 5.53832521 & 23.99808015 & 71.99424046 \\
$\mathrm{CO}$ & 2.571421225 & 5.53832521 & 23.99808015 & 35.99712023 \\
$\mathrm{Ug}$ & 2.057147559 & 5.53832521 & 14.40092166 & 35.99712023 \\
$\mathrm{Ng}$ & 2.057147559 & 14.40092166 & 14.40092166 & 23.99808015 \\
$\mathrm{Ho}$ & 2.117657024 & 5.53832521 & 23.99808015 & 71.99424046 \\
\hline
\end{tabular}

The data in the table refers to the period calculated under FFT (fast Fourier transform)

frequencies can be provided upon request. As Tan and Pedersen said, the combination of frequency domain analysis and network analysis will greatly improve data performance [76]. Taking Table 5 as an example, the values at the edges of the matrix are total values, representing the horizontal or vertical value of a certain commodity. The "TO" row represents the risk spillover of a certain commodity against other commodities in the market, which is an arrow. The "FROM" list indicates that, from the perspective of the total market size, to measure the risk spillover of a certain commodity against other commodities, it is an entry arrow corresponding to the network below. Therefore, the middle of the matrix refers to the risk spillover between the mutual one. The "NET" in the bottom row refers to the net spillover effect of a certain commodity; that is, the output value of the "IN" column offsets the input of "OUT". Figures 5-12 show the complex risk spillover network of the commodity market, which can be used to study the path of risk contagion. The network is composed of nodes and edges with arrows. The size of the node is set according to the degree of weight, and the net risk spillover amount represented by the value of the "NET" row of the spillover matrix (Table 5) is used as the weight. The larger the net spillover, the larger the node. The color of the node is determined according to the "modularity" value in the "Gephi" statistical attribute, which means that the similarity of risk between different commodities shows the same community attribute, and the color of the edge changes accordingly.

Risk spillover is a change throughout the overall system. We need to focus on not only a single commodity, but also the path conversion between different commodities in which Billio et al. introduce connectivity into the explanation [43]. We will perform analysis from three perspectives, which will also give investors more comprehensive guidance for portfolio investment. The first part is Figure 5 to Figure 12, a comprehensive visualization of the risk spillover network. The size of the node is composed of the weight of the risk spillover value between commodities and the net spillover of a single commodity; the second part for systemic risk of all commodities is just ranked at the net spillover, highlighting the top three commodities with different degrees of grey 


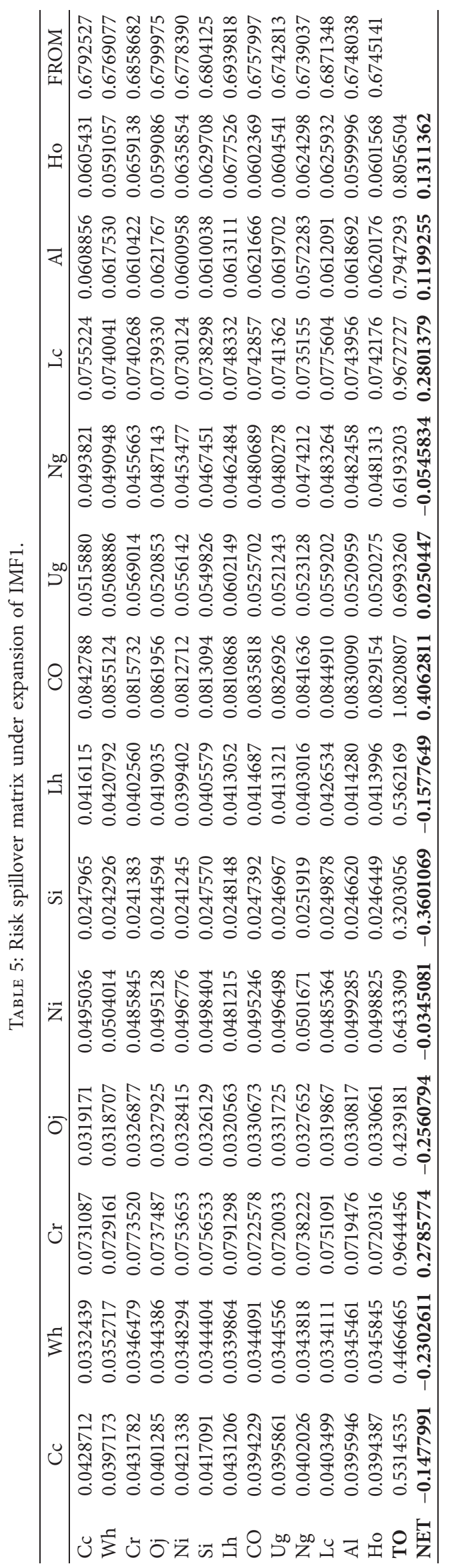




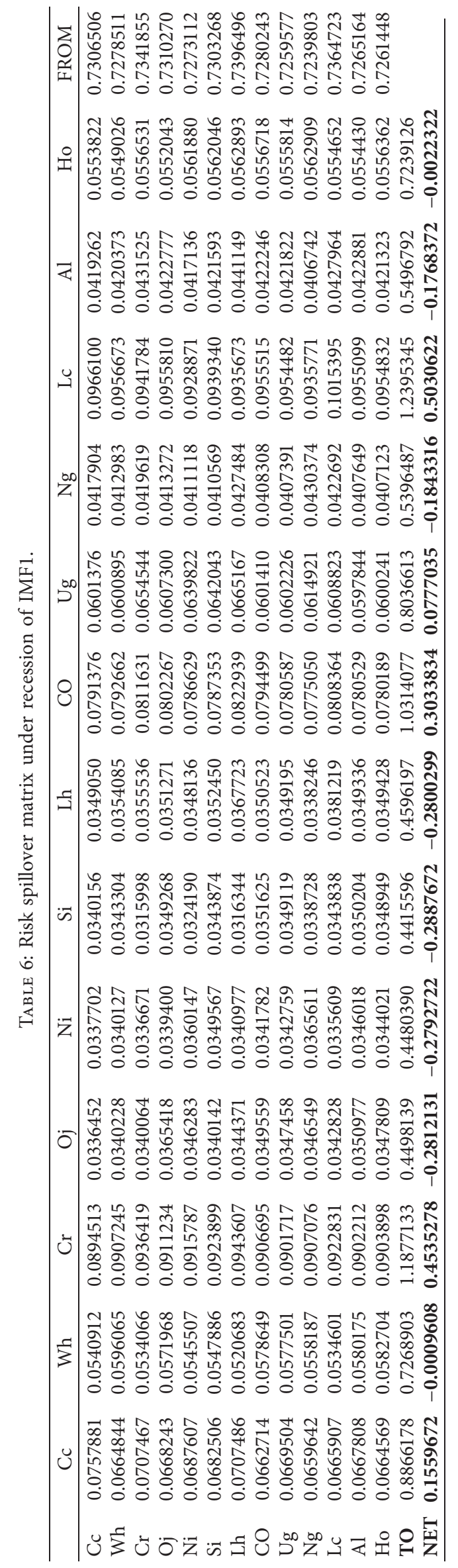




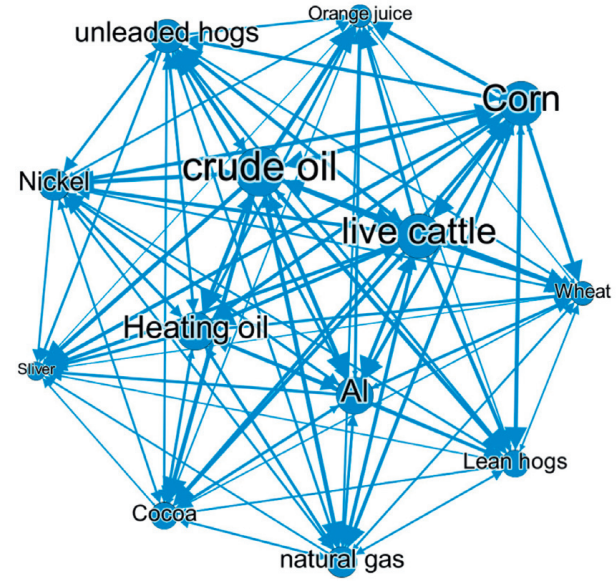

FIgURE 5: Risk spillover network under E1.

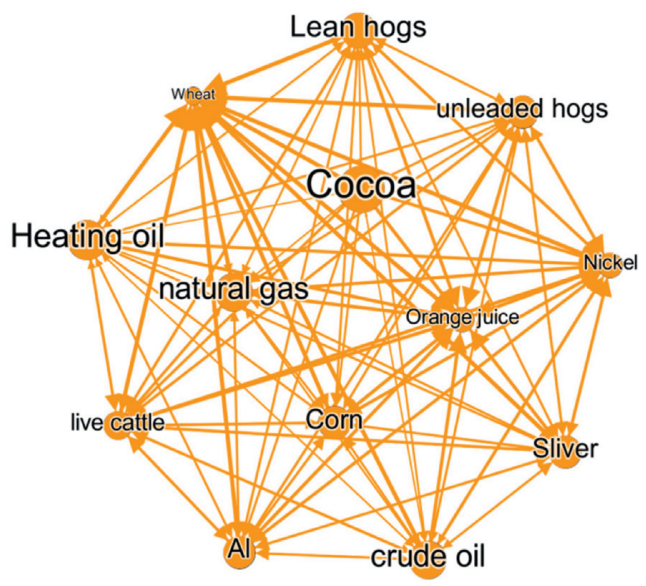

Figure 6: Risk spillover network under E2.

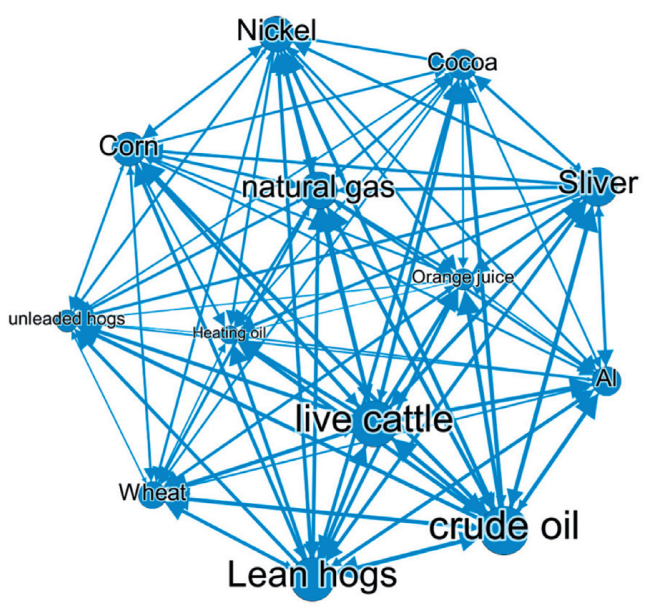

FIgURE 7: Risk spillover network under E3.

(Table 7); the third part is the risk spillover path of the top 5 under mutual commodities, meaning that one contributes to the whole (Table 8).

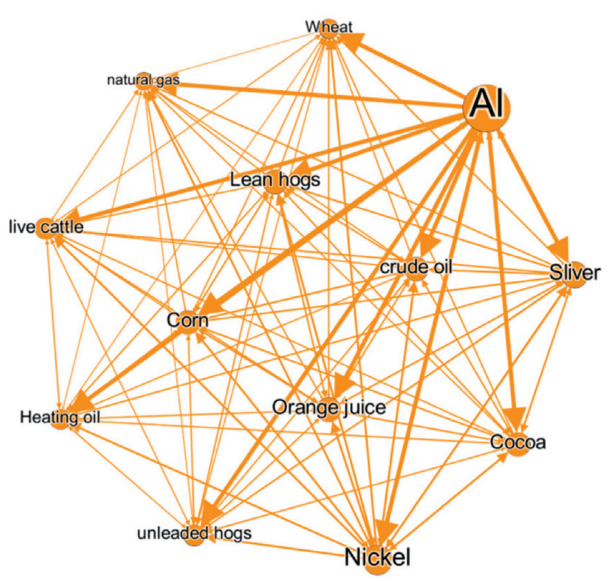

Figure 8: Risk spillover network under E4.

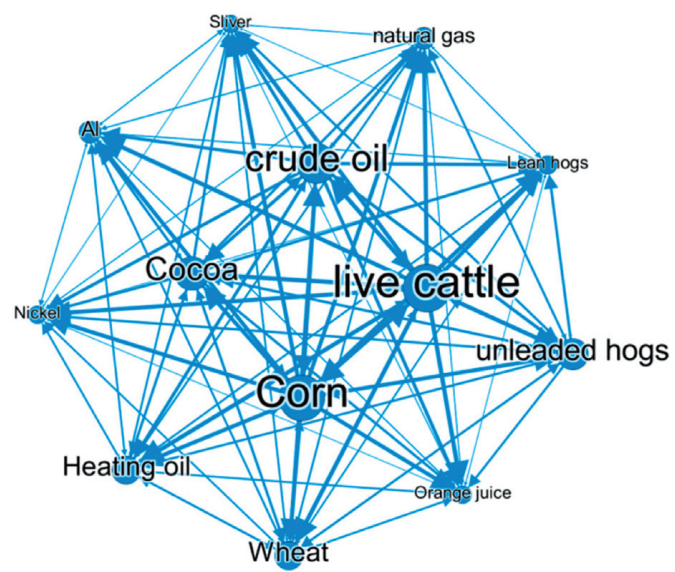

Figure 9: Risk spillover network under R1.

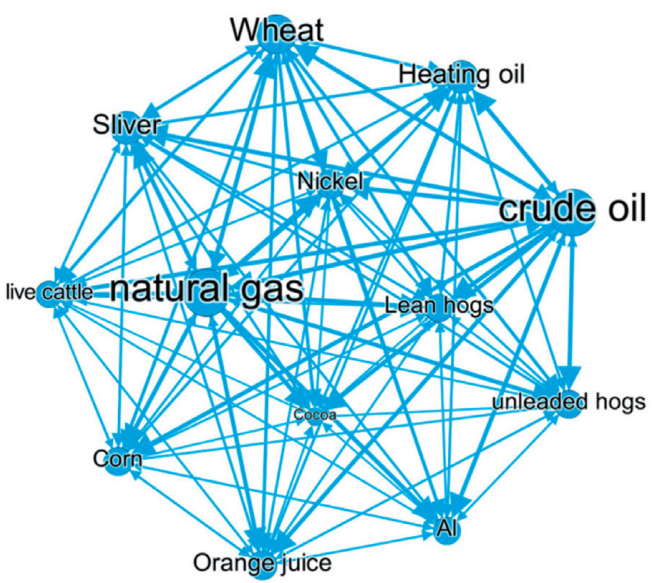

FIgURE 10: Risk spillover network under R2.

On the whole, the different frequencies under the pre cursor data did not change the "modularity" of different commodities, meaning that all characteristic is harmonious to some extent. In most cases, energy category of 


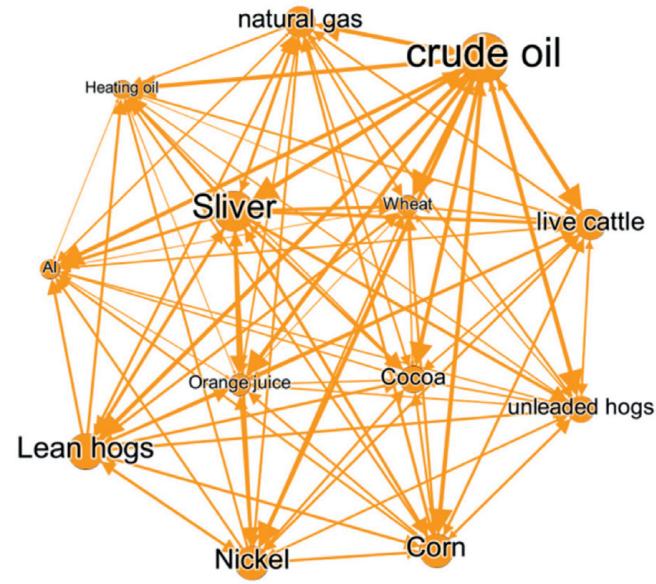

Figure 11: Risk spillover network under R3.

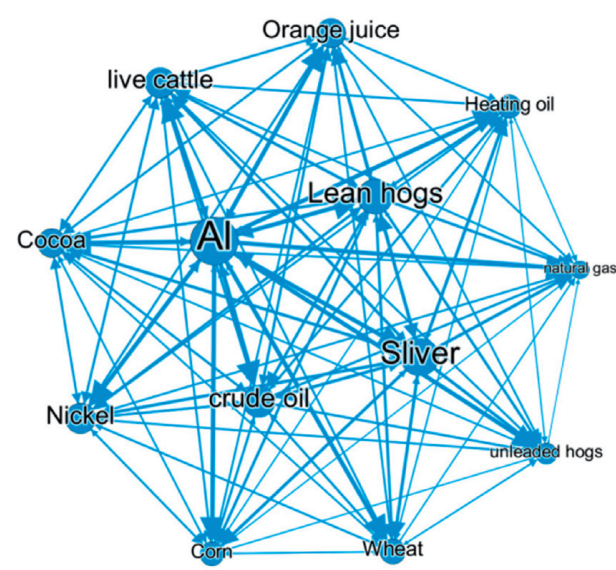

Figure 12: Risk spillover network under R4.

TABLE 7: Ranking under all regimes and IMFs at weight.

\begin{tabular}{lcccccccc}
\hline Rank & R1 & E1 & R2 & E2 & R3 & E3 & R4 & E4 \\
\hline Cocoa & 4 & 9 & 13 & 13 & 9 & 8 & 8 & 6 \\
Wheat & 6 & 11 & 3 & 1 & 11 & 10 & 9 & 12 \\
Corn & 2 & 3 & 8 & 8 & 4 & 7 & 10 & 7 \\
Orange juice & 12 & 12 & 7 & 2 & 10 & 12 & 7 & 4 \\
Nickel & 10 & 7 & 6 & 3 & 5 & 6 & 6 & 2 \\
Sliver & 13 & 13 & 4 & 7 & 2 & 4 & 2 & 3 \\
Lean hogs & 11 & 10 & 11 & 9 & 3 & 3 & 3 & 5 \\
Crude oil & 3 & 1 & 2 & 11 & 1 & 1 & 4 & 8 \\
Unleaded gas & 5 & 6 & 9 & 6 & 8 & 11 & 12 & 10 \\
Natural gas & 9 & 8 & 1 & 10 & 6 & 5 & 13 & 13 \\
Live cattle & 1 & 2 & 12 & 4 & 7 & 2 & 5 & 9 \\
Al & 8 & 5 & 10 & 5 & 12 & 9 & 1 & 1 \\
Heating oil & 7 & 4 & 5 & 12 & 13 & 13 & 11 & 11 \\
\hline
\end{tabular}

commodities is the main risk exporter, and the research of many scholars is tenable $[19,20,77]$. However, the relationship between commodities changed. Taking Figure 12 for example, metal is the risk center, and its risk spillover further exceeds that of other commodities. When faced with more changes in state, we might as well put our perspective on the place where there is a change. Under this low-frequency sequence (IMF4), it can be seen that $\mathrm{Al}$ has always remained at the risk spillover center in both states, while the energy category has been overtaken by the commodity category, as can be seen from the strong risk spillovers of orange juice and lean hogs. Under IMF2 and IMF3, the boundaries between risks of different commodities are very clear. Although crude oil is still the risk center, there are a large number of other commodities surrounding it, which may eventually develop into a competition circle for three types of commodities. In other words, the joint volatility emerged [78]. Particularly, under IMF2, during the recession of geopolitical risks, cocoa surpassed heating oil to become the center of risk spillover, and the risk level of sliver and natural gas is equivalent. When focusing on oil, we can also find that, in the long run, geopolitical risk is more closely related to crude oil, which is inconsistent with the shortterm view of Mei et al. [79]. From a vertical perspective, the network in different states maintains the position in a bigger picture, but there is a clear tendency of bigger risk degree [19].

When just concentrating on the net spillover (Table 7), we can observe that the changes in IMF1, IMF3, and IMF4 are delicate, and they are just fine-tuned under the same category. However, under IMF2, recession to expansion produced a large displacement change. When GPR is relatively strong and the sequence is under high frequency (E2), wheat is the center of risk spillover, followed by orange juice and then sliver, which is different from the risk aversion properties of oil and gold in the common perception [80-82]. However, in the period of geopolitical risk declining (R2), the risk spillover of energy commodities returned upward. It is worth noting that wheat only retreated to the third position, and the huge potential of risk in the near future may be deduced. However, during the expansion period at the same frequency, Figure 8 shows that cocoa is the risk center, which does not match the net risk spillover ranking of wheat in the table. Although it is still in the same category, this enlightens us on the path and dynamic changes analysis within the network $[39,42]$ to understand the risk transformation process in more detailed approaches.

Among the top five contagion paths that contribute to the entire commodity market (Table 8 ), the performances of recession and expansion are not the same. In the expansion period, the cumulative value continues to rise and reaches the highest value at low frequencies, while that of recession period presents an inverted "V" shape; that is, the mediumlow frequency is the point in which the risk reaches the maximum, and then the risk gradually decreases. IMF3 has also become a key point for the exchange of the two states. However, the overall contribution of the recession period to the risk is greater than that of the expansion period, which is similar to the current situation reflected by oil, and the fact that the geopolitical crisis in the Middle East has made the world pay more attention to the import and export of oil is revelatory [77]. In the specific infection path, all regimes except for E2 are consistent with the net spillover risk ranking; that is, it is more reasonable to use the product with 
TABLE 8: Infection path under all regimes and IMFs.

\begin{tabular}{|c|c|c|c|}
\hline Rank & $\mathrm{R} 1$ & $\mathrm{R} 2$ & R4 \\
\hline 1 & Live cattle $\longrightarrow$ cocoa & Natural gas $\longrightarrow$ crude oil & $\mathrm{Al} \longrightarrow \mathrm{cocoa}$ \\
\hline 2 & Live cattle $\longrightarrow$ wheat & Natural gas $\longrightarrow$ heating oil & $\mathrm{Al} \longrightarrow$ natural gas \\
\hline 3 & Live cattle $\longrightarrow$ orange juice & Natural gas $\longrightarrow \mathrm{Al}$ & $\mathrm{Al} \longrightarrow$ orange juice \\
\hline 4 & Live cattle $\longrightarrow$ crude oil & Natural gas $\longrightarrow$ wheat & $\mathrm{Al} \longrightarrow$ unleaded gas \\
\hline 5 & Live cattle $\longrightarrow \mathrm{Al}$ & Natural gas $\longrightarrow$ cocoa & $\mathrm{Al} \longrightarrow$ heating oil \\
\hline Acc. & $48 \%$ & $53 \%$ & $50 \%$ \\
\hline Rank & R3 & E1 & E4 \\
\hline 1 & Crude oil $\longrightarrow$ sliver & Crude oil $\longrightarrow$ orange juice & $\mathrm{Al} \longrightarrow$ nickel \\
\hline 2 & Crude oil $\longrightarrow$ unleaded gas & Crude oil $\longrightarrow$ wheat & $\mathrm{Al} \longrightarrow$ unleaded gas \\
\hline 3 & Crude oil $\longrightarrow$ live cattle & Crude oil $\longrightarrow$ live cattle & $\mathrm{Al} \longrightarrow$ natural gas \\
\hline 4 & Crude oil $\longrightarrow$ lean hogs & Crude oil $\longrightarrow$ cocoa & $\mathrm{Al} \longrightarrow$ lean hogs \\
\hline 5 & Crude oil $\longrightarrow$ wheat & Crude oil $\longrightarrow$ natural gas & $\mathrm{Al} \longrightarrow$ sliver \\
\hline Acc. & $59 \%$ & $42 \%$ & $78 \%$ \\
\hline Rank & E2 & E3 & \\
\hline 1 & Nickel $\longrightarrow$ wheat & Crude oil $\longrightarrow$ sliver & \\
\hline 2 & Orange juice $\longrightarrow$ wheat & Crude oil $\longrightarrow$ lean hogs & \\
\hline 3 & Lean hogs $\longrightarrow$ wheat & Crude oil $\longrightarrow$ orange juice & \\
\hline 4 & Sliver $\longrightarrow$ wheat & Crude oil $\longrightarrow \mathrm{Al}$ & \\
\hline 5 & Live cattle $\longrightarrow$ wheat & Crude oil $\longrightarrow$ live cattle & \\
\hline Acc. & $43 \%$ & $51 \%$ & \\
\hline
\end{tabular}

the strongest spillover as the sender of the risk. The special performance of E2 echoes the above-mentioned contradiction. Although it is the product with the strongest net spillover, from the perspective of the relatively large risk transmission path, wheat is just only the receiver of risks, and three of them are transmitted by lean hogs, orange juice, and live cattle, which are also agricultural commodities, which explains this noncentral position in the weighted out-degree. As argued by Gardebroek et al. [13], strong volatility interactions across commodities reduce the effectiveness of diversifying price risk. This suggests that investors and risk managers should account not only for a commodity's own dynamics but also cross-commodity volatility connectedness when predicting the volatility behavior of commodity prices.

In recent years, many sudden surges in the commodity market have become a major cause of instability in systemic risk. Moreover, as time increases, the nonlinear characteristics of systemic risk become the focus of research. We combine commodity markets with geopolitical risk and enrich the current research on systemic risk contagion in the frequency domain through the STVAR model based on EMD. Extremum is composed of "continuous increase in amplitude" and "peak superposition," and positive correlation will produce extremum; otherwise, no extremum will appear. For investors, from the perspective of preventing risks, it will become an important concern in the long run. Under different frequencies, there are differences in the reaction of risk spillovers of commodities. In the mediumhigh term, energy commodities perform poorly, and their risk center position is shaken. This may provide guidance for investors to diversify their investment portfolios throughout time. Similarly, the joint volatility between different commodities cannot be ignored. In extremely unstable energy market, the agricultural commodity market may also be a risk aversion option.

\section{Conclusion}

The starting point of this research is to show the inherent characteristics of commodity changes and to provide investors with risk portfolio options. By combining empirical mode decomposition with the STVAR model, the nonlinear research on systemic risk has been enriched from theoretical and empirical perspectives. On the one hand, our research selects precursor data containing extreme value forming factors and eliminates the data with deviations. On the other hand, we continue to expand our research from the classic frequency domain perspective to the states' transformation brought by the state variables. Finally, we analyze the reasons for the formation of extreme values from a theoretical perspective; that is to say, the extreme value is composed of "continuous increase in amplitude" and "peak superposition." At the same time, we utilize the characteristics of macro variables to replace externally assigned one by quantiles. On the whole, risk spillover of energy commodities is stronger, especially in medium-low frequency. Only in the longest term, they are replaced by metals. Under different states of geopolitical risks, the joint fluctuations between three categories of commodities have emerged. Agricultural commodities become another place for gathering risks, and metal commodities are only behind. For the holding period and portfolio investments, the decision needs comprehensive consideration.

This research reveals the rationality of introducing the internal characteristics of macro variables to divide the state, that is, using the macroeconomic market itself to influence performances of commodity market. Whether the integration of state variables into systemic risk causes changes in risk centers and spillover channels is worth investigating. Applying different state variables, such as political uncertainty, is also worthy of expansion. However, in view of the differences between the overall and partial conditions, the 
internal transformation motivation of risk spillovers in commodity markets under different frequencies still needs further study.

\section{Data Availability}

Our original data were obtained from https://cn.investing. com and http://www.policyuncertainty.com/.

\section{Conflicts of Interest}

The authors declare that they have no conflicts of interest regarding the publication of this paper.

\section{Acknowledgments}

This work was supported by the National Natural Science Foundation of China (Grant no. 71903097); the Humanity and Social Science Youth Foundation of Ministry of Education of China (Grant no. 18YJC790226); the Social Science Foundation of Jiangsu Province (Grant no. 20EYC011); and the Natural Science Foundation of Jiangsu Province (Grant no. BK20190767).

\section{References}

[1] C. A. Carter and D. MacLaren, "Price or quantity competition? Oligopolistic structures in international commodity markets," Review of International Economics, vol. 5, no. 3, pp. 373-385, 1997.

[2] D. B. B. Nguyen and M. Prokopczuk, "Jumps in commodity markets," Journal of Commodity Markets, vol. 13, pp. 55-70, 2019.

[3] S. Basak and A. Pavlova, "A model of financialization of commodities," The Journal of Finance, vol. 71, no. 4, pp. 1511-1556, 2016.

[4] T. L. Duc Huynh, T. Burggraf, and M. A. Nasir, "Financialisation of natural resources \& instability caused by risk transfer in commodity markets," Resources Policy, vol. 66, p. 101620, 2020.

[5] B. J. Henderson, N. D. Pearson, and L. Wang, "New evidence on the financialization of commodity markets," The Review of Financial Studies, vol. 28, no. 5, pp. 1285-1311, 2015.

[6] I.-H. Cheng and W. Xiong, "Financialization of commodity markets," Annual Review of Financial Economics, vol. 6, no. 1, pp. 419-441, 2014.

[7] Y. Qin, K. Hong, J. Chen, and Z. Zhang, “Asymmetric effects of geopolitical risks on energy returns and volatility under different market conditions," Energy Economics, vol. 90, p. 104851, 2020.

[8] K. Tang and W. Xiong, "Index investment and the financialization of commodities," Financial Analysts Journal, vol. 68, no. 6, pp. 54-74, 2012.

[9] H. Hong and M. Yogo, Commodity Market Interest and Asset Return predictability, Princeton University, Princeton, NJ, USA, 2010.

[10] B. Algieri and A. Leccadito, "Assessing contagion risk from energy and non-energy commodity markets," Energy Economics, vol. 62, pp. 312-322, 2017.

[11] E. Bouri, B. Lucey, T. Saeed, and X. V. Vo, "The realized volatility of commodity futures: interconnectedness and determinants," International Review of Economics \& Finance, vol. 73, pp. 139-151, 2021.
[12] A. Kumar, K. N. Badhani, E. Bouri, and T. Saeed, "Herding behavior in the commodity markets of the Asia-Pacific region," Finance Research Letters, vol. 41, p. 101813, 2020.

[13] C. Gardebroek, M. A. Hernandez, and M. Robles, "Market interdependence and volatility transmission among major crops," Agricultural Economics, vol. 47, no. 2, pp. 141-155, 2016.

[14] J. Belousova and G. Dorfleitner, "On the diversification benefits of commodities from the perspective of euro investors," Journal of Banking \& Finance, vol. 36, no. 9, pp. 2455-2472, 2012.

[15] G. Ngene, J. A. Post, and A. N. Mungai, "Volatility and shock interactions and risk management implications: evidence from the U.S. and frontier markets," Emerging Markets Review, vol. 37, pp. 181-198, 2018.

[16] Y. Xu, E. Bouri, T. Saeed, and Z. Wen, "Intraday return predictability: evidence from commodity ETFs and their related volatility indices," Resources Policy, vol. 69, p. 101830, 2020.

[17] X. Gong and B. Lin, "Forecasting the good and bad uncertainties of crude oil prices using a HAR framework," Energy Economics, vol. 67, pp. 315-327, 2017.

[18] K.-H. Wang, C.-W. Su, and M. Umar, "Geopolitical risk and crude oil security: a Chinese perspective," Energy, vol. 2021, p. 219, 119555.

[19] J. Bouoiyour, R. Selmi, S. Hammoudeh, and M. E. Wohar, "What are the categories of geopolitical risks that could drive oil prices higher? Acts or threats?" Energy Economics, vol. 84, p. 104523, 2019.

[20] C.-W. Su, K. Khan, R. Tao, and M. Nicoleta-Claudia, "Does geopolitical risk strengthen or depress oil prices and financial liquidity? Evidence from Saudi Arabia," Energy, vol. 187, p. 116003, 2019.

[21] A. Alqahtani, E. Bouri, and X. V. Vo, "Predictability of GCC stock returns: the role of geopolitical risk and crude oil returns," Economic Analysis and Policy, vol. 68, pp. 239-249, 2020.

[22] S.-H. Poon, M. Rockinger, and J. Tawn, "Extreme value dependence in financial markets: diagnostics, models, and financial implications," Review of Financial Studies, vol. 17, no. 2, pp. 581-610, 2004.

[23] F. Li and H. Perez-Saiz, "Measuring systemic risk across financial market infrastructures," Journal of Financial Stability, vol. 34, pp. 1-11, 2018.

[24] M. Oordt and C. Zhou, "Systemic risk and bank business models," Journal of Applied Econometrics, vol. 34, no. 3, pp. 365-384, 2019.

[25] A. Di Clemente, "Estimating the marginal contribution to systemic risk by A CoVaR-model based on copula functions and extreme value theory," Economic Notes, vol. 47, no. 1, pp. 69-112, 2018.

[26] P. G. Gavronski and F. A. Ziegelmann, "Measuring systemic risk via GAS models and extreme value theory: revisiting the 2007 financial crisis," Finance Research Letters, vol. 38, 2021.

[27] Y. Wang, S. Chen, and X. Zhang, "Measuring systemic financial risk and analyzing influential factors: an extreme value approach," China Finance Review International, vol. 4, 2014.

[28] D. Bakas and A. Triantafyllou, "The impact of uncertainty shocks on the volatility of commodity prices," Journal of International Money and Finance, vol. 87, pp. 96-111, 2018.

[29] O. Renn, "New challenges for risk analysis: systemic risks," Journal of Risk Research, vol. 24, pp. 1-7, 2020. 
[30] S. Ding and Y. Zhang, "Cross market predictions for commodity prices," Economic Modelling, vol. 91, pp. 455-462, 2020.

[31] L. Yang and S. Hamori, "Systemic risk and economic policy uncertainty: international evidence from the crude oil market," Economic Analysis and Policy, vol. 69, pp. 142-158, 2021.

[32] M. Prokopczuk, A. Stancu, and L. Symeonidis, "The economic drivers of commodity market volatility," Journal of International Money and Finance, vol. 98, 2019.

[33] C. Siebenbrunner, "Quantifying the importance of different contagion channels as sources of systemic risk," Journal of Economic Interaction and Coordination, vol. 16, pp. 1-29, 2020.

[34] Y.-F. Chen and X. Mu, "Asymmetric volatility in commodity markets," Journal of Commodity Markets, vol. 22, p. 100139, 2020.

[35] I. Shaikh, "On the relation between pandemic disease outbreak news and crude oil, gold, gold mining, silver and energy markets," Resources Policy, vol. 72, 2021.

[36] M. A. Naeem, F. Balli, S. J. H. Shahzad, and A. de Bruin, "Energy commodity uncertainties and the systematic risk of US industries," Energy Economics, vol. 85, 2020.

[37] C. T. Albulescu, A. K. Tiwari, and Q. Ji, "Copula-based local dependence among energy, agriculture and metal commodities markets," Energy, vol. 202, 2020.

[38] L. Yang, "Connectedness of economic policy uncertainty and oil price shocks in a time domain perspective," Energy Economics, vol. 80, pp. 219-233, 2019.

[39] W. Chen, K.-C. Ho, and L. Yang, "Network structures and idiosyncratic contagion in the European sovereign credit default swap market," International Review of Financial Analysis, vol. 72, p. 101594, 2020.

[40] T. Teräsvirta, "Specification, estimation, and evaluation of Smooth transition autoregressive models," Journal of the American Statistical Association, vol. 89, no. 425, pp. 208-218, 1994.

[41] J. Staum, M. Feng, and M. Liu, "Systemic risk components in a network model of contagion," IIE Transactions, vol. 48, no. 6, pp. 501-510, 2016.

[42] X. Liu and C. Jiang, "Multi-scale features of volatility spillover networks: a case study of China's energy stock market," Chaos: An Interdisciplinary Journal of Nonlinear Science, vol. 30, no. 3, p. 033120, 2020.

[43] M. Billio, M. Getmansky, A. W. Lo, and L. Pelizzon, "Econometric measures of connectedness and systemic risk in the finance and insurance sectors," Journal of Financial Economics, vol. 104, no. 3, pp. 535-559, 2012.

[44] D. W. King, E. S. Husebye, and R. A. W. Haddon, "Processing of seismic precursor data," Physics of the Earth and Planetary Interiors, vol. 12, no. 2, pp. 128-134, 1976.

[45] P. M. Shearer, M. P. Flanagan, and M. A. H. Hedlin, "Experiments in migration processing of SS precursor data to image upper mantle discontinuity structure," Journal of Geophysical Research: Solid Earth, vol. 104, no. B4, pp. 7229-7242, 1999.

[46] T. Rikitake, "Biosystem behaviour as an earthquake precursor," Tectonophysics, vol. 51, no. 1, pp. 1-20, 1978.

[47] C. G. Fraga, B. H. Clowers, R. J. Moore, and E. M. Zink, "Signature-Discovery approach for sample matching of a nerve-agent precursor using liquid Chromatography-Mass spectrometry, XCMS, and chemometrics," Analytical Chemistry, vol. 82, no. 10, pp. 4165-4173, 2010.
[48] E. J. Hsieh, M. R. Hoopmann, B. MacLean, and M. J. MacCoss, "Comparison of database search strategies for high precursor mass accuracy MS/MS data," Journal of Proteome Research, vol. 9, no. 2, pp. 1138-1143, 2010.

[49] V. M. Bier, "Statistical methods for the use of accident precursor data in estimating the frequency of rare events," Reliability Engineering \& System Safety, vol. 41, no. 3, pp. 267-280, 1993.

[50] Q. Ji, B.-Y. Liu, H. Nehler, and G. S. Uddin, "Uncertainties and extreme risk spillover in the energy markets: a timevarying copula-based CoVaR approach," Energy Economics, vol. 76, pp. 115-126, 2018.

[51] L. St»hle and S. Wold, "Analysis of variance (ANOVA)," Chemometrics and Intelligent Laboratory Systems, vol. 6, no. 4, pp. 259-272, 1989.

[52] E. A. Strickland, "The relationship between precursor level and the temporal effect," The Journal of the Acoustical Society of America, vol. 123, no. 2, pp. 946-954, 2008.

[53] F. X. Diebold and J. A. Lopez, "Modeling volatility dynamics," in Macroeconometrics, pp. 427-472, Springer, Berlin, Germany, 1995.

[54] Z. Wu and N. E. Huang, "On the filtering properties of the empirical mode decomposition," Advances in Adaptive Data Analysis, vol. 2, no. 4, pp. 397-414, 2010.

[55] N. E. Huang, Z. Shen, S. R. Long et al., "The empirical mode decomposition and the Hilbert spectrum for nonlinear and non-stationary time series analysis," Proceedings of the Royal Society of London. Series A: Mathematical, Physical and Engineering Sciences, vol. 454, no. 1971, pp. 903-995, 1998.

[56] N. E. Huang, M.-L. C. Wu, S. R. Long et al., "A confidence limit for the empirical mode decomposition and Hilbert spectral analysis," Proceedings of the Royal Society of London. Series A: Mathematical, Physical and Engineering Sciences, vol. 459, no. 2037, pp. 2317-2345, 2003.

[57] C. A. Sims, "Macroeconomics and reality," Econometrica, vol. 48, no. 1, pp. 1-48, 1980.

[58] G. Caggiano, E. Castelnuovo, and J. M. Figueres, "Economic policy uncertainty and unemployment in the United States: a nonlinear approach," Economics Letters, vol. 151, pp. 31-34, 2017.

[59] M. Baxter and R. G. King, "Measuring business cycles: approximate band-pass filters for economic time series," Review of Economics and Statistics, vol. 81, no. 4, pp. 575-593, 1999.

[60] R. S. Tsay, Analysis of Financial Time Series. Translate, in Analysis of Financial Time Series, 2nd ed, R. S. Tsay, John Wiley \& Sons, New York, NY, USA, 2005.

[61] L. Wang, F. Ma, T. Niu, and C. Liang, "The importance of extreme shock: examining the effect of investor sentiment on the crude oil futures market," Energy Economics, vol. 99, p. 105319, 2021.

[62] F. X. Diebold and K. Yilmaz, "On the network topology of variance decompositions: measuring the connectedness of financial firms," Journal of Econometrics, vol. 182, no. 1, pp. 119-134, 2014.

[63] V. Plakandaras, R. Gupta, and W.-K. Wong, "Point and density forecasts of oil returns: the role of geopolitical risks," Resources Policy, vol. 62, pp. 580-587, 2019.

[64] Y. Liu, L. Han, and Y. Xu, "The impact of geopolitical uncertainty on energy volatility," International Review of Financial Analysis, vol. 75, 2021.

[65] A. Gaunersdorfer and C. Hommes, "A nonlinear structural model for volatility clustering," in Long Memory in Economics, pp. 265-288, Springer, Berlin, Germany, 2007. 
[66] S. Gokcan, "Forecasting volatility of emerging stock markets: linear versus non-linear GARCH models," Journal of Forecasting, vol. 19, no. 6, pp. 499-504, 2000.

[67] W. A. Broock, J. A. Scheinkman, W. D. Dechert, and B. LeBaron, "A test for independence based on the correlation dimension," Econometric Reviews, vol. 15, no. 3, pp. 197-235, 1996.

[68] G. C. Chow, "Tests of equality between sets of coefficients in two linear regressions," Econometrica, vol. 28, no. 3, pp. 591-605, 1960.

[69] D. W. K. Andrews, "Tests for parameter instability and structural change with unknown change point," Econometrica, vol. 61, no. 4, pp. 821-856, 1993.

[70] R. E. Quandt, "Tests of the hypothesis that a linear regression system obeys two separate regimes," Journal of the American Statistical Association, vol. 55, no. 290, pp. 324-330, 1960.

[71] J. Bai and P. Perron, "Computation and analysis of multiple structural change models," Journal of Applied Econometrics, vol. 18, no. 1, pp. 1-22, 2003.

[72] Li Xia and S. Li, "Nonlinear time series forecasting model based on EMD and DVG and its application research," Chinese Management Science, pp. 1-11, 2021.

[73] P. K. Narayan and S. S. Sharma, "An analysis of time-varying commodity market price discovery," International Review of Financial Analysis, vol. 57, pp. 122-133, 2018.

[74] C. Kerschner, C. Prell, K. Feng, and K. Hubacek, "Economic vulnerability to peak oil," Global Environmental Change, vol. 23, no. 6, pp. 1424-1433, 2013.

[75] J. Noguera-Santaella, "Geopolitics and the oil price," Economic Modelling, vol. 52, pp. 301-309, 2016.

[76] C. Tan and C. N. S. Pedersen, Financial Time Series Forecasting Using Improved Wavelet Neural Network, Univesity of Copenhagen, Copenhagen, Denmark, 2009.

[77] J. Krane and K. B. Medlock, "Geopolitical dimensions of US oil security,” Energy Policy, vol. 114, pp. 558-565, 2018.

[78] R. S. Pindyck and J. J. Rotemberg, "The excess co-movement of commodity prices," The Economic Journal, vol. 100, 1990.

[79] D. Mei, F. Ma, Y. Liao, and L. Wang, "Geopolitical risk uncertainty and oil future volatility: evidence from MIDAS models," Energy Economics, vol. 86, p. 104624, 2020.

[80] M. B. Triki and A. Ben Maatoug, "The GOLD market as a safe haven against the stock market uncertainty: evidence from geopolitical risk," Resources Policy, vol. 70, 2021.

[81] D. G. Baur and L. A. Smales, "Gold and geopolitical risk," 2018, https://ssrn.com/abstract=3109136 or http://dx.doi.org/ 10.2139/ssrn.3109136.

[82] D. G. Baur and L. A. Smales, "Hedging geopolitical risk with precious metals," Journal of Banking \& Finance, vol. 117, p. 105823, 2020. 